\title{
Endocardial lesion in a case of Takayasu's arteriopathy
}

\author{
M. K. Chhetri, N. C. Pal, Chandrika Neelakantan, N. D. Chowdhury, \\ and K. C. Basu Mullick \\ From the Institute of Postgraduate Medical Education and Research, Calcutta 20, India
}

The clinical findings and the necropsy report of a I4-year-old girl suffering from Takayasu's arteriopathy have been presented. In addition to the typical arterial changes, thickening and puckering of the aortic valve and a patch of thickening in the left atrial endocardium were shown at necropsy. The histology of this lesion was found to be identical with the arterial intimal changes. It has been postulated that Takayasu's arteriopathy may rarely extend to the valvular and mural endocardium of the heart, producing cardiac murmurs. Similar cases with cardiac murmurs reported earlier and attributed to associated rheumatic endocarditis were probably due to the same pathological process extending to the endocarditis.

Since the first description of the pulseless disease by Takayasu (1908) followed by Oonishi (1908), several clinical reports have appeared from different countries (Shimizu and Sano, I95I; Cosma et al., 1959; Misra, Prakash, and Agrawal, 1959; Pahwa, Pandey, and Gupta, 1959; Isaacson, 196I; Danaraj, Wong, and Thomas, 1963; Sen et al., 1963; Strachan, 1964) including detailed pathological studies and necropsy findings (Caldwell and Skipper, I96I ; Nasu, 1963; Danaraj et al., 1963; Vinijchaikul, 1967). Most of these cases were from Asia.

The disease has shown a predilection for young women, the basic pathology being in the intima and medial layers of the aorta and its main branches, occasionally affecting the pulmonary trunk. There is conspicuous hyperplasia and fibrosis of these layers, often progressing to gradual obliteration of the lumen of the vessel. In addition, the media shows diffuse inflammatory changes with degeneration of the elastic fibres leading to ectasia. The adventitia may show proliferation of the connective tissue with hyalinization along with inflammation.

The clinical presentation depends upon the stage of progression of the disease and the site and extent of arterial involvement. Thus, in the early pre-pulseless phase (Strachan, 1964), diffuse systemic symptoms simulating sys- temic lupus erythematosus may occur, and in the late phase, stenosis or dilatation of the aorta and its major branches may give rise to protean manifestations, the commonest being intermittent claudication, hypertension, thromboembolic phenomena, headache, dimness of vision, and effort angina.

In this paper, we wish to report a girl suffering from Takayasu's arteriopathy, who had both clinical and necropsy confirmation of aortic valve and left atrial endocardial involvement.

\section{Case report}

A r4-year-old schoolgirl was admitted to hospital complaining of giddiness and headache associated with nausea and occasional vomiting of three months' duration. Her illness had started two years back with pain in both the eyes and dimness of vision. Lately, she had also developed intermittent claudication, exertional dyspnoea, and palpitation. She had some oedema in the legs before admission. She gave no rheumatic or any other significant history. Physical examination revealed a girl of moderate height and average build. She was not anaemic and had no oedema in the legs. Her pulse was 120 a minute, regular. Respiratory rate was 18 a minute. She was apyrexial. She had prominent carotid artery pulsations. The apex beat was palpable at the fifth left intercostal space in the midclavicular line and was left ventricular in type. A left parasternal heave 
was present. A loud first sound and a grade 2 middiastolic rumble was heard in the mitral area. In the aortic area there was an early diastolic murmur which was best heard in the third left intercostal space. The pulmonary second sound was accentuated. A clear systolic murmur was heard in the neck over the carotids and along the back on either side of the spine down to the renal angles. A systolic bruit was also heard in the abdomen anteriorly. All the arterial pulses were palpable but weaker on the left upper and lower extremities compared to the right. The blood pressure in the right arm was I40/I IO, left arm IIO/70, right leg I40/IIO, and left leg I24/90 mm. Hg. The liver was just palpable and tender. The spleen was palpable about $2.5 \mathrm{~cm}$. below the costal margin. Fundus oculi was normal. Findings in other systems were non-contributory. A provisional diagnosis of diffuse non-specific arteritis with hypertension, mitral stenosis, aortic incompetence, and congestive heart failure was made.

Routine blood examination gave $\mathrm{Hb}$ I2 g./100 ml., total white cell count 6,300 per cu.mm. with neutrophils 68 per cent, lymphocytes 28 per cent, monocytes 2 per cent, and eosinophils 2 per cent. Erythrocyte sedimentation rate was $20 \mathrm{~mm}$. in the first hour. Routine urine and stool examination revealed no abnormality. The results of other investigations were as follows: fasting blood sugar $95 \mathrm{mg}$./100 ml., urea $21 \mathrm{mg} . / 100 \mathrm{ml}$., creatinine $0.6 \mathrm{mg}$./100 ml., NPN $20 \mathrm{mg}$./100 ml., SGOT 106 units/ml., SGPT 48 units/ml., PBI 5.I $\mu \mathrm{g} . / 100$ $\mathrm{ml}$. Excretion of adrenaline in 24 -hour urine was $9 \mu \mathrm{g}$. and noradrenaline $66 \mu \mathrm{g}$. Throat swab culture showed Staphylococcus pyogenes, Streptococcus viridans, and Neisseria catarrhalis. Urine culture was negative. The Rose-Waaler and LE cell tests were negative. The skin and muscle biopsy showed no evidence of arteritis. Radiology of the heart showed an enlarged cardiac silhouette, with enlargement of the right atrium, right ventricle, and left ventricle. Electrocardiogram showed normal sinus mechanism with a heart rate of 120 per minute, normal axis, vertical heart, PR 0.14 sec., QRS $0.06 \mathrm{sec}$, QT $0.28 \mathrm{sec}$., the picture suggesting left atrial enlargement and right ventricular preponderance. Rapid sequence intravenous pyelography showed a smaller right kidney with delayed function. Isotope renogram showed a reduced blood flow through the right kidney with evidence of obstruction. Function of the left kidney was normal.

During the period of investigations, she was treated with digoxin, diuretics, and multivitamins without much effect. As the tachycardia persisted, propranolol $20 \mathrm{mg}$. twice daily was added to the regimen, and her pulse rate settled down. The dose of propranolol was then halved (ro mg. b.d.). After a short uneventful period, before angiographic studies could be done, she suddenly developed severe chest pain which was followed by peripheral circulatory failure. Rigorous treatment was of no avail. Three hours later she developed a pericardial rub and a weak paradoxical pulse, and expired shortly afterwards.

At necropsy the pericardial cavity contained

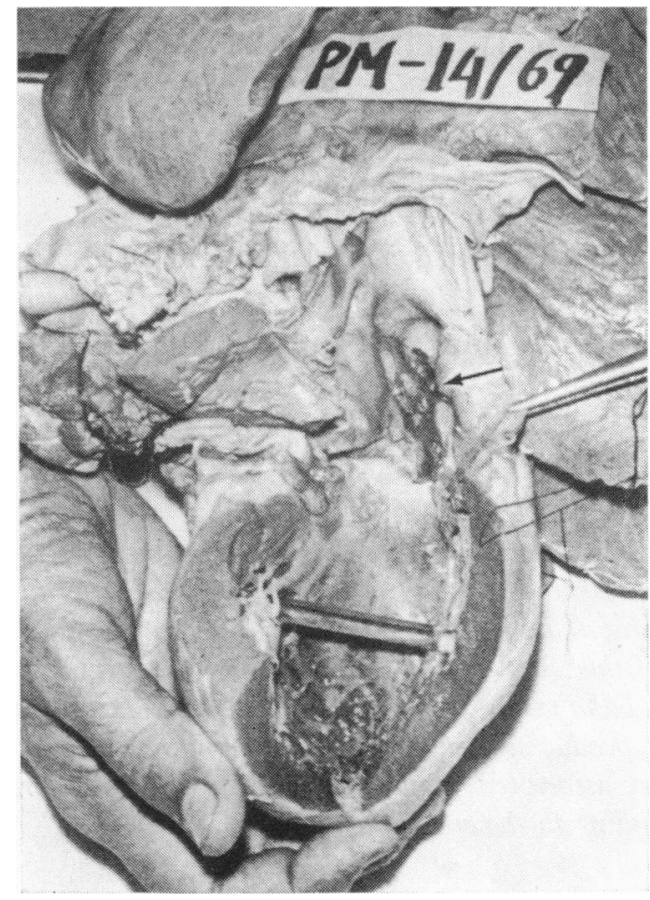

FI I. I Note the thickening of the left atrial endocardium covered by clot (arrow).

about $300 \mathrm{ml}$. serosanguinous fluid. The heart showed left ventricular hypertrophy. The cusps of the mitral valve were normal, but on the wall of the left atrium immediately above the posterior cusp of the mitral valve there was a rough and raised patch in the endocardium (Fig. I). Aortic cusps were thickened, rigid, and firm. Coronary vessels were normal. Immediately above the aortic valve the aorta showed patchy areas of intimal thickening looking like wax drops (candle dripping). The thickened aortic cusps resembled the intimal thickening in gross appearance. Near the origin of the innominate artery there was a patchy thickening of the aorta, and at the point of take off this artery showed conspicuous narrowing of its orifice. The abdominal aorta, from a little above the origin of the renal arteries to a short distance above its bifurcation, was much thickened, and its lumen which was narrowed was occupied by a fresh clot. The origin of the right renal artery was much narrowed compared to the origin of the left renal artery (Fig. 2). The wall of the right renal artery also showed thickening.

Microscopical examination of the thickened patch in the left atrium showed raised endocardium formed by loose connective tissue lined over by endothelium. This appearance was exactly similar to that of the intimal thickening of the aorta (Fig. 3). The myocardium showed signs of hypertrophy with no stigmata of any rheumatic infection or other inflammatory conditions. Section of the aorta showed involvement of the intima with conspicuous thickening and at some places organizing thrombi. The media showed patchy 
degeneration of the muscle and elastic fibres. Near the vasa vasorum occasional inflammatory cells were found, which, however, were not exactly perivascular. The adventitia showed round cell infiltration consisting mostly of lymphocytes. The lesions were typical of Takayasu's arteriopathy. Sections of the lungs and liver showed the picture of chronic venous congestion.

\section{Comments}

The essential lesion in Takayasu's arteriopathy is non-specific thickening of the various layers of the artery mainly affecting the intima and causing its progressive occlusion. Though predominantly an arterial disease, murmurs of aortic incompetence and mitral stenosis have been reported in some of the cases (Danaraj et al., 1963; Vinijchaikul, 1967). In one such case at necropsy (Vinijchaikul's series, 1967), there was a slightly thickened and stenotic mitral valve, which was regarded by the author as rheumatic in origin. In yet another of his cases there was dilatation of the aortic ring to account for the aortic diastolic murmur, and this was also considered by him to be of rheumatic origin.

In the present case also, murmurs of mitral stenosis and aortic incompetence were heard clinically and they were regarded as rheumatic, though the patient had offered no such history in the past. Necropsy, however, disproved this contention. On the other hand, a patch of endocardial thickening of the left atrium was seen, a feature not reported so far in cases of Takayasu's disease. The histological picture of the endocardial thickening was identical with that of the intimal sclerosis noticed in the aorta. Thus, this may be presumed to be caused by an identical pathological process. The patient had clinical evidence of mitral stenosis though mitral valve at necropsy appeared normal. It is possible that the genesis of the mitral diastolic murmur was in some way related to the impediment to the blood flow offered by the thickened, rough endocardium near the entrance of the mitral ring. The few reports on the aortic diastolic murmur heard in this disease have been ascribed to the dilatation of the aortic ring caused by Takayasu's lesion of the supravalvular portion of the aorta (Sandring and Welin, 196I ; Lessof and Glynn, 1959; Jervell, 1954). Danaraj et al. (1963) demonstrated by aortography a slightly dilated ascending aorta with moderate degree of regurgitation of dye into the left ventricle. The genesis of the aortic diastolic murmur in our case was evidently due to the puckering and thickening of the valve cusps and dilatation of aortic ring, probably resulting from the same pathological

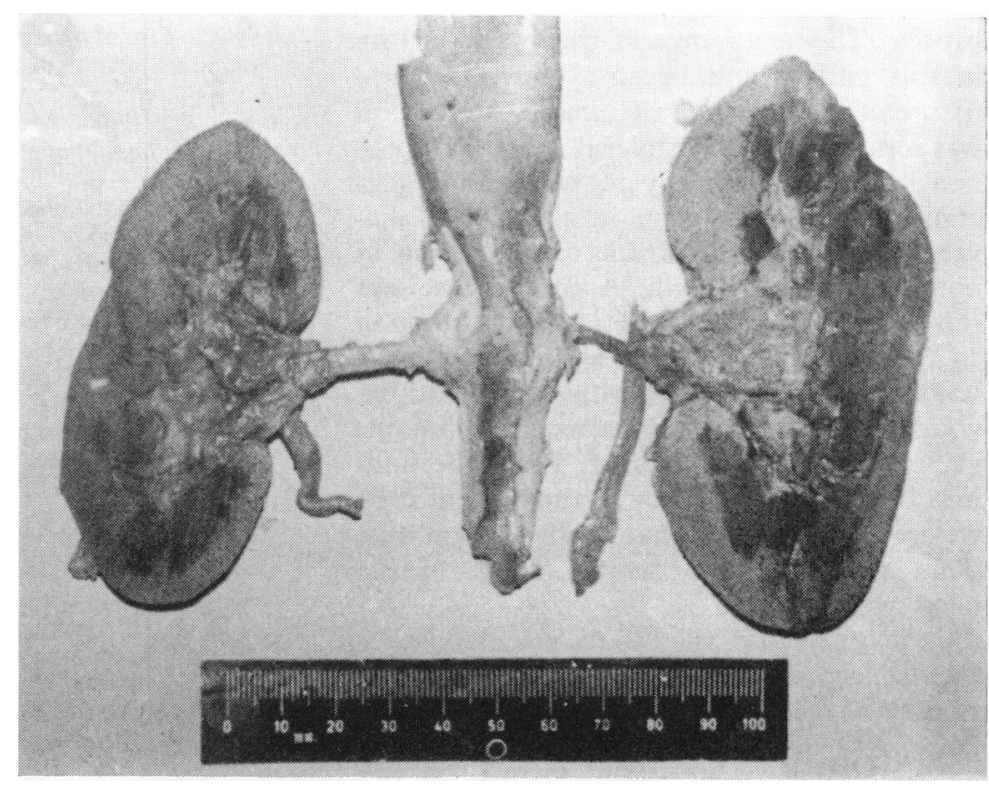

FIG. 2 Conspicuous thickening of the aortic wall from little above the origin of the renal arteries, with consequent narrowing of the lumen. The right renal artery is thickened and the right kidney is somewhat atrophic.

FIG. 3 Photomicrograph of the section of the aorta. Note the thickening of the intima and patchy destruction of the media. (Haematoxylin and eosin. $\times 120$.

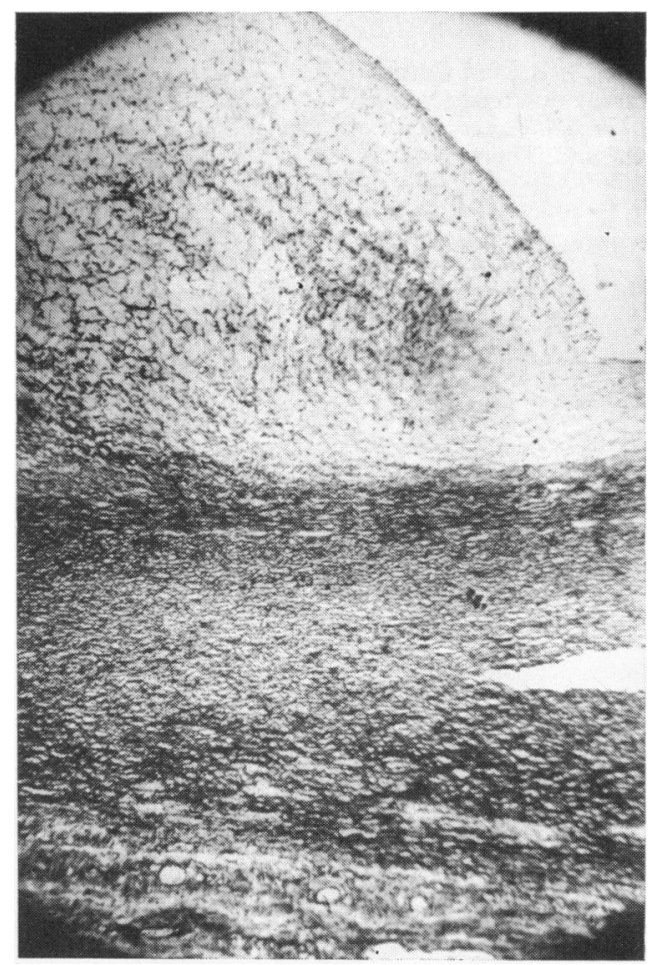


process. In the absence of rheumatic history in this patient and because of the atypical nature of the lesions, a rheumatic background was considered improbable. Judge et al. (1962) had observed at necropsy puckering and thickening of the aortic valve in a case of Takayasu's disease, and considered the lesion as not rheumatic in origin. A similar case was reported by Marquis et al. (I968) in a boy of 19. The question naturally arises whether the lesions in this type of arteritis can extend beyond the aorta into the heart involving the valve or mural endocardium. From the findings obtained at necropsy in the present case, we are of the opinion that this is a possibility. This requires confirmation from further necropsy studies.

Like others, we failed to discover any aetiological factor in this case. The stigmata of rheumatic fever, rheumatoid arthritis, syphilis, and polyarteritis nodosa were absent. This is one of the most frustrating aspects of this disease. The causative factor or factors have so far remained obscure.

We are grateful to the Surgeon Superintendent, SSKM Hospital, and the Director, Institute of Postgraduate Medical Education and Research, Calcutta-20, for allowing us to publish this paper.

\section{References}

Caldwell, R. A., and Skipper, E. W. (1961). Pulseless disease, a report on five cases. British Heart fournal, 23, 53.

Cosma, J., Maruyama, Y., Pettet, J. R., and Cutshall, V. (I959). Takayasu's disease, a case report with an angiocardiographic study. Circulation, 20, 267.

Danaraj, T. J., Wong, H. O., and Thomas, M. A.
(1963). Primary arteritis of aorta causing renal artery stenosis and hypertension. British Heart Fournal, 25, I53.

Isaacson, C. (196I). An idiopathic aortitis in young Africans. Fournal of Pathology and Bacteriology, 8r, 69.

Jervell, A. (1954). Pulseless disease. American Heart fournal, 47, 780 .

Judge, R. D., Currier, R. D., Gracie, W. A., and Figley, M. M. (1962). Takayasu's arteritis and the aortic arch syndrome. American fournal of Medicine, 32, 379.

Lessof, M. H., and Glynn, L. E. (1959). The pulseless syndrome. Lancet, I, 799.

Marquis, Y., Richardson, J. B., Ritchie, A. C., and Wigle, E. D. (1968). Idiopathic medical aortography and arteriopathy. American fournal of Medicine, 44, 939.

Misra, S. S., Prakash, S., and Agrawal, P. L. (1959). Pulseless disease (Takayasu's syndrome). American Heart fournal, 57, 177.

Nasu, T. (1963). Pathology of pulseless disease. Angi$o \log y, 14,225$.

Oonishi, K. (I908). Acta Societatis Ophthalmologicae Faponicae, 12, 554. (Cited by Nasu, 1963.)

Pahwa, J. M., Pandey, M. P. N., and Gupta, D. P. (1959). Pulseless disease, or Takayasu's disease, a case report. British Medical fournal, 2, 1439.

Sandring, H., and Welin, G. (I96I). Aortic arch syndrome with special reference to rheumatoid arthritis. Acta Medica Scandinavica, 170, I.

Sen, P. K., Kinare, S. G., Engineer, S. D., and Parulkar, G. B. (1963). The middle aortic syndrome. British Heart fournal, 25, 610.

Shimizu, K., and Sano, K. (I95I). Pulseless disease. Fournal of Neuropathology and Clinical Neurology, I, 37.

Strachan, R. W. (1964). The natural history of Takayasu's arteriopathy. Quarterly fournal of Medicine, 33, 57.

Takayasu, M. (1908). A case with peculiar changes in central retinal vessels. Acta Societatis Ophthalmologicae faponicae, 12, 554.

Vinijchaikul, K. (1967). Primary arteritis of the aorta and its main branches (Takayasu's arteriopathy). American fournal of Medicine, 43, I5. 